\title{
Autologous rectus sheath sling for treatment of vault prolapse after hysterectomy.
}

1. FCPS (Obs \& Gynae) Associate Professor Obs \& Gynae Nishtar Medical University Multan.

2. FCPS (Obs \& Gynae)

Professor Obs \& Gynae Nishtar Medical University Multan.

3. FCPS (Obs \& Gynae) Professor Obs \& Gynae Nishtar Medical University Multan.

4. FCPS (Obs \& Gynae)

Assistant Professor Obs \& Gynae Nishtar Medical University Multan

5. FCPS (Obs \& Gynae)

Assistant Professor Obs \& Gynae Nishtar Medical University Multan

6. FCPS (Obs \& Gynae)

Assistant Professor Obs \& Gynae Nishtar Medical University Multan.

Correspondence Address: Dr. Syeda Ali

Department of Obs \& Gynae

Nishtar Medical University Multan.

Syedasadiq74@gmail.com

Article received on:

08/08/2020

Accepted for publication:

22/10/2020

\section{Syeda Ali $^{1}$, Shahid Rao², Mehnaz Khakwani ${ }^{3}$, Saima Yasmin ${ }^{4}$, Shazia Siddiq ${ }^{5}$, Saima Mustafa ${ }^{6}$}

ABSTRACT... Objective: Determine the duration and post-operative complications of surgery in patients who underwent rectus sheath sling for correction of vault prolapse. We started doing this novel technique and found it very safe with least side effects so wanted to study it. Study Design: Experimental study. Setting: Nishtar Hospital Multan Pakistan. Period: July 2016 to June 2018. Material \& Methods: Patients were applied autologous sling of rectus sheath at Nishtar Hospital Multan and were followed for 2 years. Patients with diabetes mellitus and any other chronic disease were excluded. Patients who had previous surgery for vault prolapse were also excluded from the study. Data were recorded and analyzed using IBM-SPSS version 23.0, percentages are given for previous surgery duration (how long before the previous surgery was done), duration of current surgery, post-operative fever, post -operative urinary tract infection(UTI), duration of stay in the hospital after surgery, parenteral analgesia requirement. Parameters were tested using Pearson Chi Square test with type of previous surgery. Results: The total number of patients in the study were 19.The mean age of the patients was 59.7 years $(\mathrm{SD}= \pm 9.7)$ and mean weight was $59.4 \mathrm{~kg}(\mathrm{SD}= \pm 12.5)$. The duration of surgery was less than 1 hour in $84 \%$ of patients. Same percentage had less than 36 hours requirement of postoperative parenteral analgesia and thus less than 2 days of post-operative stay in hospital. Postoperatively $31.6 \%$ had fever, $26.3 \%$ had Urinary tract infection. On 2 years follow-up of this surgery, no patient had any recurrence of vault prolapse and $85.7 \%$ showed no coital difficulty. Conclusion: This surgical procedure is a simple, time saving method with less complications and is best suited for low resource countries like Pakistan.

Key words: $\quad$ Rectus Sheath Sling, Vault Prolapse, Post-operative Complications.

Article Citation: Ali S, Rao S, Khakwani M, Yasmin S, Siddiq S, Mustafa S. Autologous rectus sheath sling for treatment of vault prolapse after hysterectomy. Professional Med J 2021; 28(4):475-480.

https://doi.org/10.29309/TPMJ/2021.28.04.5939

\section{INTRODUCTION}

Vaginal vault prolapse occurs when the upper portion of vagina loses its normal shape and sags into the vaginal canal and outside the vagina. It may occur alone or along with the prolapse of bladder (cystocele), urethra (urethrocele), rectum (rectocele) and small intestine (enterocele). ${ }^{1}$ The incidence of vault prolapse was $11.6 \%$ when hysterectomy had been done for genital prolapse and $1.8 \%$ when it has been done for other benign diseases. $^{2}$ The preferred treatment of vault prolapse has been either vaginal sacrospinous fixation ${ }^{3}$ or abdominal sacrocolpopexy. ${ }^{4}$ Both these techniques in experienced hands had a cure rate in excess of $90 \% .^{5-7}$ Most surgeons prefer the abdominal route $^{8}$ because in sacrospinous fixation as the stitches may not be applied under direct vision so there may be damage to internal pudendal or sacral vessels or damage to the sciatic nerve. ${ }^{9}$ Sacrocolpopexy which is done abdominally has also certain complications like bleeding, genuine stress incontinence, detrusor instability, voiding problems and most importantly the mesh may get infected ${ }^{10}$, as it is a foreign material.

In this paper, we are presenting a method which we have tried in this experimental study of 19 patients. This is a modified rectus sheath facial sling which is used for vault suspension. ${ }^{11}$ This is a novel method and the number of studies are insufficient to assess its efficacy. We found this method safe for the patient and easier for a low resource setting like ours, like lesser duration of 
surgery and less post-operative complications so we decided to work on this.

\section{MATERIAL \& METHODS}

This experimental study was conducted from July 2016 to June 2018 in Nishtar Hospital Multan Pakistan. Patients came with vault prolapse after having an abdominal or a vaginal hysterectomy. We had total of 19 patients who were included in this study. Patients with diabetes mellitus and any other chronic disease were excluded. Patients who had previous surgery for vault prolapse were also excluded from the study. Informed consent was designed for this new method and was taken and a questionnaire was filled before and after the surgery. Ethical approval was also taken.

After giving patients spinal anesthesia, patient's vagina was packed by a roll gauze for easier identification of vault at surgery, with one end under her right leg for perioperative removal. Foleys catheter was placed in urethra. Then abdomen was opened via a Pfannensteil incision. The fascia above the rectus sheath was separated from it and transverse incisions were given in the form of a ribbon on the rectus sheath about the length of the skin incision. A band of rectus sheath is thus made and divided in the midline. The breadth of this ribbon like sling is kept at least $2 \mathrm{~cm}$. In this way right and left slings are produced. The medial edges of the slings are placed in the artery forceps and now the peritoneal cavity is opened. These slings are inserted into the peritoneal cavity with the help of an artery forceps along the lateral margins of the rectus muscle and again held by the same. Now the vault is identified and held by Allis's forceps. And the roll gauze now removed by the assistant. Peritoneum on the vault is incised and bladder is separated, if adherent with the vault, so that there is place for adequate stitching available above and behind the vault. With the help of prolene no. 1 the slings are stitched to the posterosuperior aspect of the vault.

We had to make sure that there is no twisting in the slings. Vault was pulled up and supported by the slings of rectus sheath. Now the rectus sheath is stitched with vicryl no. 1 with special emphasis at the level of inguinal rings. Abdomen is closed and posterior repair is also done. Patients were put on intravenous fluids and pain killers and ambulated within 24 hours. Foleys catheter were taken out at 24 hours post-surgery. Temperature and postoperative pain was noted. Most of the Patients were discharged on day 2 postoperatively and were called on $8^{\text {th }}$ post-operative day for removal of subcuticular prolene stitches. Patients were followed up after 2 years for recurrence and any problem during coitus. Data were recorded and analyzed using IBM-SPSS version 23.0, percentages are given for previous surgery duration (how long before the previous surgery was done), duration of current surgery, post-operative fever, post-operative urinary tract infection, duration of stay in the hospital after surgery, parenteral analgesia requirement after surgery, recurrence and coital problems at 2 year follow up. Association of these parameters was tested using Pearson Chi Square test with type of previous surgery. P- Values less than 0.05 were considered statistically significant.

\section{RESULTS}

63.3\% women who were included in the study had vault prolapse after vaginal hysterectomy and $36.8 \%$ after total abdominal hysterectomy.

Table-I reports the baseline Characteristics of studied samples and the findings in the present study.

The association of studied parameters is given with the type of previous surgery. In samples of TAH, $85.7 \%$ had previous surgery within 5 years, $42.9 \%$ have post-operative fever, $57.1 \%$ have UTI, and $42.1 \%$ have more than an hour duration of surgery, $71.4 \%$ had postoperative analgesic requirement of less than 36 hours and less than 2-days of stay. All $100 \%$ samples found no recurrence within 2-years, $85.7 \%$ showed no difficulty in sex, whereas among samples with $\mathrm{VH}$ surgery, 50\% had last surgery in less than 5-years of duration, $25 \%$ have post-operative fever, $8.3 \%$ have UTI. all $100 \%$ have less than an hour duration of surgery, $91.7 \%$ had parenteral analgesic requirement for less than 36 hours and less than 2-days of stay, 83.3\% samples found had no recurrence within 
2-years. $58.3 \%$ showed no difficulty in sex at 2 years follow up. Post-operative UTI and duration
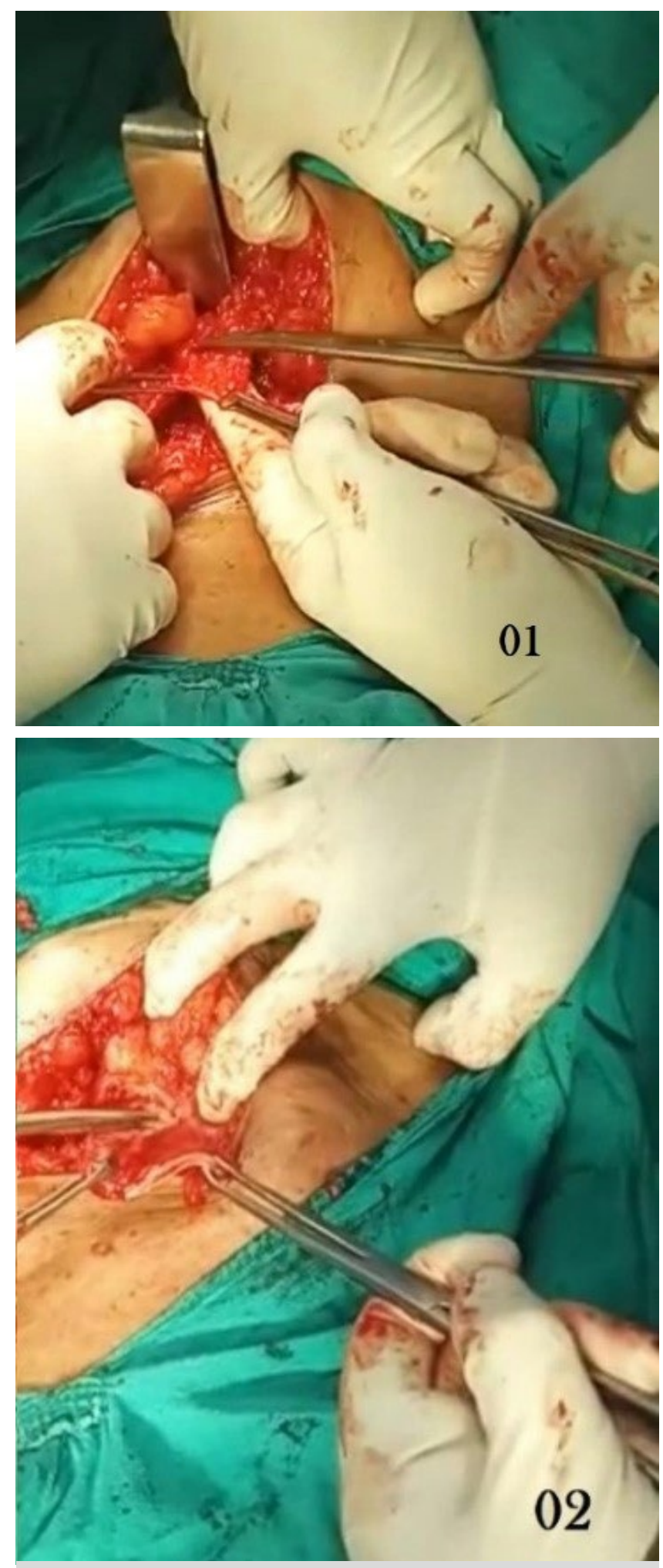

Formation of rectus sheath sling of surgery gives significant association with type of previous surgery. $p<0.05$.
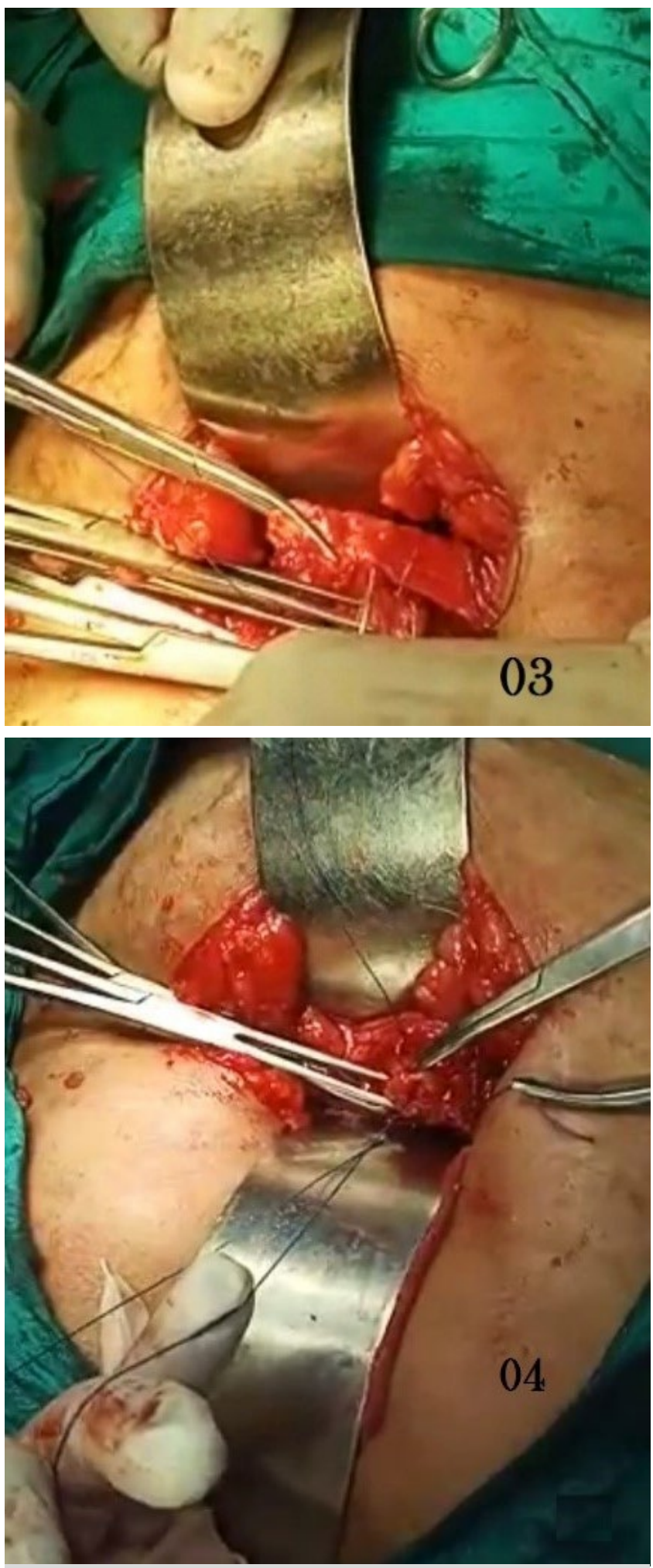

Stitching of rectus sheath sling with the vault 


\begin{tabular}{|c|c|c|c|}
\hline \multicolumn{2}{|c|}{ Characteristics } & \multirow{2}{*}{$\begin{array}{c}\mathbf{N} \\
12\end{array}$} & \multirow{2}{*}{$\begin{array}{c}\% \\
63.2\end{array}$} \\
\hline Previous & $<5$ years & & \\
\hline surgery & $6-10$ years & 6 & 31.6 \\
\hline duration & >10years & 1 & 5.3 \\
\hline \multirow{2}{*}{$\begin{array}{l}\text { Post-operative } \\
\text { Fever }\end{array}$} & Yes & 6 & 31.6 \\
\hline & No & 13 & 68.4 \\
\hline \multirow{2}{*}{$\begin{array}{l}\text { Post-operative } \\
\text { UTI }\end{array}$} & Yes & 5 & 26.3 \\
\hline & No & 14 & 73.7 \\
\hline \multirow{2}{*}{$\begin{array}{l}\text { Duration } \\
\text { of current } \\
\text { surgery }\end{array}$} & $<1$ hour & 16 & 84.2 \\
\hline & $>1$ hour & 3 & 15.8 \\
\hline \multirow{2}{*}{$\begin{array}{l}\text { Post-operative } \\
\text { analgesic }\end{array}$} & $<36$ hours & 16 & 84.2 \\
\hline & $>36$ hours & 3 & 15.8 \\
\hline \multirow{2}{*}{$\begin{array}{l}\text { Post-operative } \\
\text { stay duration }\end{array}$} & $<2$ days & 16 & 84.2 \\
\hline & $>2$ days & 3 & 15.8 \\
\hline \multirow{2}{*}{ Recurrence } & $\begin{array}{l}\text { No recurrence } \\
\text { in } 2 \text { years }\end{array}$ & 17 & 89.5 \\
\hline & Died & 2 & 10.5 \\
\hline \multirow{4}{*}{ Sex Problem } & No difficulty & 13 & 68.4 \\
\hline & Difficulty & 1 & 5.3 \\
\hline & Abstinence & 3 & 15.8 \\
\hline & Death & 2 & 10.5 \\
\hline Age (Years) & Mean $\pm S D$ & $59.7 \pm 9.7$ & \\
\hline Weight (Kg) & Mean $\pm S D$ & $59.4 \pm 12.5$ & \\
\hline
\end{tabular}

\section{DISCUSSION}

In our study of 19 patients, $63.3 \%$ patients had vault prolapse after vaginal hysterectomy and 36.8 $\%$ had prolapse after abdominal hysterectomy. Autologous rectus sheath sling was applied and among $84.2 \%$ of patients the total duration of surgery was less than an hour. $84.2 \%$ had less than 36 hours of parenteral analgesic requirement and less than2 days of post - operative stay in hospital. Postoperatively $31.6 \%$ had mild fever, $26.3 \%$ had Urinary tract infection. At 2 years follow up no recurrence rate was detected in $89.5 \%$ patients, as 2 patients died before 2 year follow-up because of unrelated reasons.

Incidence of vault prolapse varies in different setups but appears to be increased fivefold after vaginal hysterectomy. ${ }^{12}$ We didn't have a data of our hospital regarding the incidence of vault prolapse in vaginal and abdominal hysterectomies but the patients included in our study had precedent vaginal hysterectomy in
$63.3 \%$ and abdominal hysterectomy in $36.8 \%$ of patients. This point needs to be evaluated in future research. Anterior abdominal wall colpopexy using autogenous strips of rectus fascia is a simple operation for repair of post hysterectomy prolapse of the vaginal vault providing the desirable results with less complications. A study done by Rajev Mahindra showed minor post-operative complications like vomiting, fever and urinary retention and there were no major complications observed. ${ }^{13}$ It is similar to our study in which the incidence of UTI was only $26.3 \%$ and post-operative fever was $31.6 \%$. No patient had urinary retention in our study.

A similar study was done in Services Hospital Lahore in 2013, which included patients of uterovaginal prolapse. In contrast to this study, our patients had undergone surgery, either abdominal or vaginal hysterectomy for the correction of prolapse and had come again for correction of vault prolapse. In that study, the same findings of no major intraoperative or postoperative complications were seen. ${ }^{14}$

Our study provides the association of studied parameters with the type of previous surgery. In patients who had undergone abdominal hysterectomy the incidence of postoperative fever, UTI and duration of surgery is more i.e.42.9\%, $57.1 \%$ and $28.6 \%$ ( more than $1 \mathrm{hr}$ ). Whereas in patients who had previous vaginal hysterectomy, $25 \%$ had post- operative fever, only $8.3 \%$ had UTI and all of these patients had duration of surgery less than an hour. Analgesic requirement was also low in patients with vaginal hysterectomy. No previous study had worked on such association in the past so our study is unique in this regard.

Regarding follow up at 2 years, 2 patients among the vaginal hysterectomy group died due to reasons unrelated to surgery, there was no recurrence in the remaining 17 patients.

Coital problems were seen in only 14.3 percent of the group with previous abdominal hysterectomy. But in patients having vaginal hysterectomy, out of 12 , as 2 patients had died and remaining 3 were elderly widows so 58.3 percent of the group 
were having coitus with no difficulty. Anterior abdominal wall colpopexy using autogenous strips of rectus fascia to repair post-hysterectomy prolapse of the vaginal vault has the advantage of preservation of a physiologically useful vagina, its caliber and depth with no reported recurrence. ${ }^{15}$

Another study is available in which rectus sheath sling was used for prevention of vault prolapse at the time of abdominal hysterectomy with considerable success but unfortunately this procedure hasn't been studied much. ${ }^{16}$ This technique can be applied in future research as a means to prevent vault prolapse especially after abdominal hysterectomy.

\section{CONCLUSION}

Autologous rectus fascial sling for the treatment of vault prolapse is a useful and relatively simple procedure. This procedure has low morbidity, with almost no recurrence rates. This makes it a favorable alternative to abdominal sacrocolpopexy and vaginal sacrospinous fixation with better outcomes especially in low resource settings like Pakistan. Our study has certain limitations because of the less number of patients and because it is still a novel procedure so more research is warranted.

Copyright@ 22 Oct, 2020.

\section{REFERENCES}

1. Lentz GM (2012). Anatomic defects of the abdominal wall and pelvic floor. In GM Lentz et al., eds., Comprehensive Gynecology, 6th ed., pp. 453-474. Philadelphia: Mosby Elsevier.

2. Marchionni M, Bracco GL, Checcucci V, Carabaneanu $A$, Coccia EM, Mecacci $E$ et al. True incidence of vaginal vault prolapse. Thirteen years' experience. JReprod Med 1999; 44:679-84.

3. Carey MP, Slack MC. Transvaginal sacrospinous colpopexy for vault and marked utervaginal prolapse. Br J Obstet Gynaecol 1994; 101:536-40. DOI: 10.1111/ j.1471-0528.1994.tb13158.x.

4. Bimbaum SJ. Rational therapy for the prolapsed Vagina. Am J Obstet Gynecol 1973; 153:140-6.
5. Morley GN, Dalency JO, Sacrospinous ligament fixation for eversion of vagina. Am J Obstet Gynecol 1988; 158:872-9. DOI: 10.1016/0002-9378(88)90088-9.

6. Aspesi G, Rovetha E, Presti M. Surgical management and prevention of vaginal vault prolapse. Surg Gynecol Obstet; 1992:175:233-7.

7. Addison WA, Livengood $\mathrm{CH}$, Sutton GP, Parker RT. Abdominal sacral colpopexy with mercilene meshin the retroperitoneal position in the management of post hysterectomy vault prolapse of enterocele. Am J Obstet Gynecol 1991; 153:140-6. DOI: 10.1016/00029378(85)90098-5.

8. Stanton SI. Vaginal prolapse. in: shaw RW, Sautter WP, Stanton SI editors. Gynaecology Edinburgh: Churchill Livingstone, 1992:437-47.

9. Creighton SM, Stanton SI. The surgical management of vaginal vault prolapse. Br J Obstet Gynaecol1991; 98:1150-54. DOI: 10.1111/j.1471-0528.1991.tb15368.x.

10. Valaitis SR, Stanton SI. Sacrocolpopexy: A retrospective study of a clinician's experience. $\mathrm{Br} \mathrm{J}$ Obstet Gynaecol 1994; 101:518-22 DOI: 10.1111/j.14710528.1994.tb13154.x.

11. Hawkins J, Hudson C. Surgery for axial displacement and prolapse of uterus and vaginal vault In: Hawkins J, Hudson C, editors. Shaws Text book of operative gynaecology. Edinburgh: Churchill Livingstone, 1977:236-38.

12. Barrington JW, Edwards G. Posthysterectomy vault prolapsed. Int Urogynecol J Pelvic Floor defunct. 2000; 11(4):241-5.doi:10.1007/s001920070033.

13. Mahendru R. Effective and safe innovation for the management of vault prolapse. J Turk Ger gynaecol Assoc. 2010; 11(2):69-72. DOI: 10.5152/jtgga.2010.01.

14. Iqbal S, Arif W, Noreen A: Autologous Rectus Sheath Sling for treatment of uterovaginal prolapse. PJMHS 707 P J M H S Vol. 7, NO. 3, JUL - SEP 2013.

15. De Lima OA, Valente CA. Rectus fascia colpopexy for complete prolapsed of the vaginal vault after hysterectomy. Int Surg. 1987; 72:119.

16. Khanum RA, Sultana N, Begum K, Zohora TH, Rashid HU, Mridha TK. Total abdominal hysterectomy with vault sling significantly reduces vault prolapse in vulnerable women. The Orion Medical Journal May 2007; 27:455-57. 


\section{AUTHORSHIP AND CONTRIBUTION DECLARATION}

\begin{tabular}{|c|c|c|c|}
\hline Sr. \# & Author(s) Full Name & Contribution to the paper & Author(s) Signature \\
\hline 1 & Syeda Ali & $\begin{array}{l}\text { Conceived and designed study, Data } \\
\text { collection , Analysis, Manuscript } \\
\text { writing, Interpretation Principal } \\
\text { investigator. }\end{array}$ & $\begin{array}{l}\text { Syeda } \\
\text { Aiei }\end{array}$ \\
\hline 2 & Shahid Rao & $\begin{array}{l}\text { Data collection, Study design, } \\
\text { Manuscript writing, Final reading, } \\
\text { review and final approval of } \\
\text { manuscript. }\end{array}$ & Metring fellen \\
\hline 3 & Mehnaz Khakwani & $\begin{array}{l}\text { Data collection, Study design, Final } \\
\text { reading, Review and final approval of } \\
\text { manuscript. }\end{array}$ & 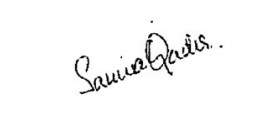 \\
\hline 4 & Saima Yasmin & $\begin{array}{l}\text { Data collection, Analysis, Editing of } \\
\text { manuscript. }\end{array}$ & $S_{L, a z b}$ \\
\hline 5 & Shazia Siddiq & $\begin{array}{l}\text { Data collection, analyzing editing of } \\
\text { manuscript. }\end{array}$ & \\
\hline 6 & Saima Mustafa & $\begin{array}{l}\text { Data collection, analyzing editing of } \\
\text { manuscript. }\end{array}$ & Samia \\
\hline
\end{tabular}

